\title{
Novel Approaches to the Development and Application of Informetric and Scientometric Tools
}

\section{Special Issue of Journal of Data and Information Science on ISSI2019 Conference-Part II}

\author{
Giuseppe Catalano ${ }^{1}$, Cinzia Daraio ${ }^{1 \dagger}$, Jacqueline Leta ${ }^{2}$, Henk F. Moed ${ }^{1}$, \\ Giancarlo Ruocco ${ }^{1}$, Xiaolin Zhang ${ }^{3}$ \\ ${ }^{1}$ Sapienza University of Rome, Italy \\ ${ }^{2}$ Instituto de Bioquímica Médica / UFRJ, Brazil \\ ${ }^{3}$ National Science Library, Chinese Academy of Sciences, China
}

This is the second part of the Journal of Data and Information Science (JDIS) Special Issue on ISSI 2019, the $17^{\text {th }}$ International Conference on Scientometrics and Informetrics (ISSI2019) held in Rome, on 2-5 September 2019 and includes additional 10 selected posters presented during the conference largely expanded by the authors afterwards.

The papers included in this volume have been grouped in three broad themes:

- Indicators \& Databases (4 papers);

- Social context, Innovation, and Policy (3 papers);

- Application domains (3 papers).

Below we report a summary of the contents of the papers inviting JDIS readers to read the full versions available on the journal's website.

\section{Indicators \& Databases}

The papers included in this topic range from new indicators' proposal to investigation of research dynamics at micro-level, from the citation links in the Crossref Open Citation Index to automatic extraction of information from universities' website.

\footnotetext{
† Corresponding author: Cinzia Daraio (E-mail: daraio@diag.uniroma1.it).
}

Citation: Catalano, G., Daraio, C., Leta, J., Moed, H.F., Ruocco, G., \& Zhang, X.L. "Novel approaches to the development and application of informetric and scientometric tools." Journal of Data and Information Science, vol. 5, no. 4, 2020, pp. 1-4. https://doi. org/10.2478/jdis-20200041 


\section{Editorial}

Rochim et al. (2020) introduce a new index, called D-offset, to be added as a complement to the H-index value. This new index is able to differentiate researchers with the same H-index and is based on Jain's Fairness index.

Chen and Han (2020) propose a micro investigation of research dynamics modelling topic disappearance by using a cross-collection topic model. They investigate the research impact through "citations of citations" content analysis and examine the research dynamics of the artificial intelligence researcher Geoffrey Hinton's publications.

Chudlarský and Dvořák (2020) analyze the proportion of Web of Science (WoS) citation links from the Czech Technical University of Prague that is represented in the Crossref Open Citation Index and find that 53.7\% of WoS citation links are present in the Crossref Open Citation Index.

Bianchi et al. (2020) investigate the potentialities of recent approaches for an automatic knowledge extraction directly from the universities' websites. They highlight the flexibility of the proposed approach in collecting indicators about the efficiency of universities' websites and their effectiveness in disseminating key contents.

\section{Social context, Innovation, and Policy}

The three papers of this topic focus on the investigation of the relationship between research conceptualization and research agendas, co-authoring in academic publications and investigation on international collaboration and network analysis.

Santos and Horta (2020) analyze the association between how researchers conceptualize research and their strategic research agendas using a dataset of more than 8,500 researchers worldwide across all scientific fields. They find a relatively strong association between researchers' conceptions of research and their research agendas.

Iwami et al. (2020) investigate co-authoring in academic publications of the Osaka University exploring potentials of collaborations with five countries identified as candidates for the future global campuses of Osaka University based on three factors, co-authoring relations, GDP growth, and population growth.

$\mathrm{Hu}$ et al. (2020) investigate the international collaboration at the level of authors, institutions, and countries, through bibliometric and social network analysis in artificial intelligence, analyzing 38,224 papers from 1985 to 2019 in the core collection database of WoS. They find that in the field of artificial intelligence, the number of published papers is increasing every year, and collaboration with more

Journal of Data and Information Science than three authors, collaboration between two countries, and collaboration within institutions are the three main levels of collaboration patterns. 


\section{Application domains}

The three papers included in this topic deal with the analysis of funding mechanisms in the Social Science and Humanities, investigation of topic evolution through natural language processing and text mining and exploitation of the e-Lattes platform to map the Brazilian scientific output on the Zika virus.

Must (2020) investigates the evolution of the Social Science and Humanities thematic pattern through three funding instruments since 2007 with the aim of checking to what extent the EU Framework Program (FP) affects/does not affect research on national level, and to highlight hot topics from a given period with the help of text analysis. The results show that in the majority of cases words do not overlap between FP and nationally funded projects.

Shen and Wang (2020) introduce an open source natural language processing and text mining method for topic evolution, emerging topic detection and research trend forecasting for all kinds of data-tagged text. It is based on the open source VOSviewer and Microsoft Office, including a thesaurus for data clean-up and a LOOKUP function for comparative analysis.

Sampaio et al. (2020) in their paper analyze a set of e-Lattes CVs of Zika researchers registered on the Lattes Platform to map the Brazilian scientific response to the Zika virus crisis.

\section{References}

Bianchi, G., Bruni, R., Daraio C., Laureti Palma, A., Perani, G., \& Scalfati, F. (2020). Exploring the potentialities of automatic extraction of university webometric information. Journal of Data and Information Science, 5(4), 43-55.

Chen, X.L., \& Han, T. (2020). A micro perspective of research dynamics through "citations of citations" topic analysis. Journal of Data and Information Science, 5(4), 19-34.

Chudlarský, T., \& Dvořák, J. (2020). Can Crossref citations replace Web of Science for research evaluation? The share of open citations. Journal of Data and Information Science, 5(4), 35-42.

Hu, H.T., Wang, D.B., \& Deng, S.H. (2020). Global collaboration in artificial intelligence: Bibliometrics and network analysis from 1985 to 2019. Journal of Data and Information Science, 5(4), 86-115.

Iwami, S., Shimizu, T., Empizo, M.J.F., Gabayno, J.L.F., Sarukura, N., Fujii, S., \& Sumimura, Y. (2020). Current status and enhancement of collaborative research in the world: A case study of Osaka University. Journal of Data and Information Science, 5(4), 75-85.

Must, Ü. (2020). Priorities for social and humanities projects based on text analysis. Journal of Data and Information Science, 5(4), 116-125.

Rochim, A.F., Muis, A., \& Sari, R.F. (2020). A discrimination index based on Jain's fairness index to differentiate researchers with identical H-index values. Journal of Data and Information Science, 5(4), 5-18.

Journal of Data and Information Science

http://www.jdis.org https://www.degruyter.com/view/j/jdis 


\section{Editorial}

Sampaio, R.B., de Abreu Batista, A., Ferreira, B.S., Barreto, M.L., \& Mena-Chalco, J.P. (2020). Scientometric analysis of research output from Brazil in response to the zika crisis using e-Lattes. Journal of Data and Information Science, 5(4), 137-146.

Santos, J.M., \& Horta, H. (2020). The association between researchers' conceptions of research and their strategic research agendas. Journal of Data and Information Science, 5(4), 56-74.

Shen, X., \& Wang, L. (2020). Topic evolution and emerging topic analysis based on open source software. Journal of Data and Information Science, 126-136.

\section{(c) $\odot \odot \ominus$}

This is an open access article licensed under the Creative Commons Attribution-NonCommercialNoDerivs License (http://creativecommons.org/licenses/by-nc-nd/4.0/).

Journal of Data and Information Science 